\title{
Is a happy anthropologist a good anthropologist?
}

By Katherine L. Smith (University of Wales, Lampeter)

The purposes of this paper are to introduce and contextualise my recent doctoral fieldwork research in Higher Blackley, North Manchester, England, and to discuss the difficulties in understanding and monitoring the fragmentation of the self in fieldwork (Coffey 1999:121). How do we deal, as ethical but also politically motivated human beings, with responses or actions which make us cringe, make us afraid, confused or unhappy? How do we reconcile our own moral, ethical and political perspectives with those of individuals who hold very different perspectives in the field? A Weberian tradition has legitimated research programmes that attempt to equate objectivity with an attitude of emotional disengagement, cognitive objectivity and moral indifference. When faced with anger, fear or depression, a sense of "passionate detachment" was often a desired state for me; however, it was a desire that proved to be part of the very fabric of fieldwork and a result of the "self" which I brought into the field. Through asking the question "Is a happy anthropologist a good anthropologist?" I will demonstrate that, in a rhetorical sense, this question opens up many avenues for elaboration and exploration, in attempts to better understand the world in which we may find ourselves during our fieldwork experiences.

\section{Introduction}

The purpose of this paper is to explore a way in which I found myself dealing with epistemological dilemmas of positioning and personal emotional reactions in my fieldwork in Higher Blackley, North Manchester, England. I will address the ways in which we, as researchers, but also as ethically and politically motivated human beings, are faced with discourses and actions in fieldwork situations which can be very surprising and challenging compared to the personal, ethical and moral standpoints that we bring to specific settings. Reflecting on my fieldwork experience of being physically assaulted in a racially-motivated attack during fieldwork, I will explain the analytical dilemmas I faced in attempting a "passionate detachment" whilst also coming to terms with the notion that the emotional reactions of researchers in fieldwork are inextricably tied up with our research and writing up (Hovland 2007). Ultimately, this article demonstrates that through the course of fieldwork and writing up there is a unique challenge to the anthropologist: that at the same time the researcher can experience and analyse fieldwork experiences.

In part, my intentions carry with them the hope of a reminder for anthropologists that fieldwork may not always be as it is remembered (cf. Gupta and Ferguson 1997). During my fieldwork, I often imagined myself having a tremendous sense of achievement once I had completed my time in the field. I had anticipated feeling a sense of achievement through carrying out long-term, systematic, ethnographic fieldwork in an area of a city I found uneasy, listening to individuals express racist thoughts or provide forms of logic behind what I perceived to be some rather 
unpalatable views, missing my husband and my home, staying dedicated to this one area of research for 12 months and eventually returning home and writing about it. Perhaps such an achievement would allow me to reflect upon my fieldwork experience with fondness, despite the emotional and intellectual challenges and predicaments that I faced as fieldwork continued. I feel it is important to address the question "Is a happy anthropologist a good anthropologist?" as I have learned that it can be impossible to separate personal, emotional feelings from fieldwork experience; yet, this is not necessarily unproductive. "Rather than necessarily attempting to minimise reactivity during fieldwork, it is more productive to monitor it" (Ellen 1984:18); yet, a monitoring process is nevertheless an affecting and ever-changing process. As Rapport (2002:152) has argued, "the presumption of this reflexivity including our sociological reflection upon our reflexivity - is an intrinsic part of modern social practice", as we "constantly examine and reform our practices in the light of incoming information". There were times in fieldwork when I felt overwhelmed by sadness, depression, anger and fear. There were misunderstandings and mishaps which were of course informative, but actually experiencing them aroused emotions that I had never encountered before. In my fieldwork I attempted to develop a method to deal with experiences that shook me, disturbed me or hurt me, and here, I explore the interlocking methodological and theoretical implications.

\section{Contextualising the field}

Over a period of 12 months, I conducted ethnographic fieldwork in Higher Blackley, North Manchester, England. I explored local and individual expectations of local and national government and when the metaphor of "fairness" is employed in addressing issues of immigration and multi-culturalist policies. The implications of my study are both particular and general, and it makes two kinds of contributions. First, it examines specific individual idioms of "fairness" and "belonging" in Higher Blackley, seeking to specify how each narrative is marked by the interlocking concerns and effects of geographical origin, familiarity between individuals and groups, political orientations, ethnicities, gender, and shared histories of racial and "cultural" imaginations in Higher Blackley. Second, it explores local and individual concepts of "fairness" and governmental prescriptions of "equality" to question whether or not there are discrepancies and disparate connotations concerning these concepts. The ethnographic examples I use to address these issues highlight the micro-political processes within which resistance and illegal actions may be justified by individuals in attempts to deal with the ever-changing global, national and regional political processes that appear unfamiliar and challenging to the everyday lives of individuals living in Higher Blackley.

Located about four miles north of the city centre of Manchester, Higher Blackley lies on both sides of a two-mile stretch of Victoria Avenue, between Rochdale Road in the east and Heaton Park in the west. It is situated next to the M60 motorway which is a ring road encircling Greater Manchester. There is a supermarket near Heaton Park, scattered smaller markets and corner shops, two post offices, three secondary schools, three primary schools, three banks, four doctors' surgeries, three dentists and a local library with internet access. Higher Blackley is comprised mostly of council housing "estates" and is an area where many governmental policies are visible on various levels; whether such decisions concern taxation, housing, transport, commerce, immigration, industrialisation or international trade. Higher Blackley is an area that 
has a historically-informed categorical status of "working-class", although many individuals refused to associate themselves with any class status, as such. In the course of my research, most of my co-conversationalists in Higher Blackley generally identified themselves as "white" and "English", whereas the fluid notion of being "working-class" was rarely if ever discussed by most individuals unless to point to an abhorrence of a "middle-class" way of being. Notions of "middle-class-ness" were created in opposition to local ideological and desirable embodiments of integrity, humility and humbleness - not "going above your station" or thinking of oneself as "better" than anyone else.

There is no doubt in my mind that having come from California and being a citizen of the United States contributed to how I was perceived by individuals in Higher Blackley. Indeed, the "self" whom I brought into the field affected my fieldwork and the responses I have received from respondents (Agar 1980, Burgess 1984, Ellen 1984, Eriksen 1991). I was the "outsider" who came in, became an active member of the local communities, seemingly enjoyed the ways of life in Higher Blackley and progressively learned ways in which to relate with individuals on more familiar levels. The fact that I am from the United States was periodically discussed in conversations, and was often used as a tool with which to signal my seemingly innate differences amongst many individuals (such as my geographical origin, accent, dress sense, the fact that I could afford to be studying for a doctorate). Signals such as these were also used as ways of relating through humour, as I would often hear Americanised colloquial phrases such as "Howdee yank!" "What's up?" "Yanks love it here!" I was forgiven for cheering for the "wrong" football team (unintentionally, of course) and I was treated to "Hot Toddies" and what it is to really have a night out. In more generalising terms, I was viewed as a researcher, a student, a woman, a wife, and as white, American, class-less, vulnerable and impressionable. Frequently, I was referred to as the "doe-eyed Yank", which, although it surprised me when I first heard my nick-name, allowed me to recognise that even the most silenced reactions I may have held were visible and thus subject to interpretation in any given moment.

I must admit that my own emotional reactivity during fieldwork would not have been what it was, nor would it have provided the following insights into my own personal experiences of the social world around me, had I not spent the amount of time I did forging the relationships, engaging in the activities and accepting the challenges to my own personal points of view, in "the field" of Higher Blackley and with the people there. I spent a substantial amount of time in a local social club, Clare's, in Higher Blackley, forging relationships, conducting interviews and eventually obtaining a job behind the bar, serving drinks, crisps and nuts to the regulars. It was in Clare's that I learned most about ways of relating, belonging and, particularly, the local sense of humour, within which my co-conversationalists and I would regularly engage; assessing and maintaining the sensitive boundaries of interpersonal relationships.

\section{A fine balance: emotions and distance}

I sometimes think of the act of doing ethnographic fieldwork as if one was a pebble and wanted to study a pond; one does that by tossing oneself into that pond. The implications appear to be endless, particularly when monitoring one's own emotional reactivity (Caplan 2003, Hastrup and Elsass 1990) and paying attention to the "fragmentation of the self" which Amanda Coffey (1999:121) explains. I feel it is important to continue to acknowledge these points: fieldworkers (especially those 
who are beginning fieldwork for the first time) may find themselves in unfamiliar (especially emotional) positions that they may have read something about in anthropological literature, but which they may find particularly perplexing and untried as their situations and interpretations will be unique to their fieldwork locations, situations, respondents and the time in which fieldwork is conducted, thus pointing to the conjunctural nature of all ethnography (Piña-Cabral 2000:341).

Attempts to "step back" and look at uncomfortable situations from an "analytical perspective", as I put it in my fieldwork diary, may provide an outlet in an attempt to remove personal engagement with a situation (Adler and Adler 1998, Hendry 1992, Marcus 1995). However, it is only a temporary remedy, as the ethnographer is bound to his or her field and respondents for an extended amount of time and must consider his or her own reactions, how they are interpreted by others, how they affect the "self" and the "other" in the long term, as well as how this may be directing the fieldwork methods, objectives and positionalities of the researcher (Ferrell and Hamm 1998, see for example Hendry 1992). When I felt ineffective because of emotional reactions such as anger or fear, I would initiate a process of introspection, asking myself why it was that I was angry or fearful or sad, and how this might help with my overall objectives for being in Higher Blackley. In my fieldwork diary, I referred to this process of introspection as "putting experiences into an analytical perspective". This involved creating a sense of distance between me, as researcher, and the fieldwork experience. Laden with significant interpretive implications, this method has underpinning notions of objectivity which I realised, only after fieldwork, are hardly attainable; rather, this process of introspection, placing experiences into an "analytical perspective" and reflecting on this perspective in retrospect, are results of the self which I brought into the field and, thus, more recognisable upon reflection.

The ethnographer must consider his or her own reactions, how they are interpreted by others, how they affect the "self" and the "other" in the long term, and how this may be directing the fieldwork methods and objectives of the researcher (Ferrell and Hamm 1998; for examples see Caplan 2003:25, Harvey and Fillitz 2006:220). Donna Haraway (1991:192) is eloquent on this point, stating,

A commitment to mobile positioning and to passionate detachment is dependent on the impossibility of innocent "identity" politics and epistemologies as strategies for seeing from the standpoints of the subjugated in order to see well. One cannot "be" either a cell or molecule - or a woman, colonized person, labourer, and so on - if one intends to see and see from these positions critically.

Reflection in my diary on the various experiences of individuals and me, in fieldwork, is simply that: a reflection which is ever-changing in the anthropological lenses through which I view it. Personal emotional reactions that I experienced for the first time in fieldwork are experienced in new ways in retrospect and upon reflection. The following is an example of physical violence that I experienced during fieldwork. This experience has allowed me to interrogate significant questions of not only violence, but also issues of racism and patriotism, as well as the embodiment of anger: the fading sense of fear and the onset of anger and desire for retaliation.

\section{A speedy step forward}

It was February, 2007, and I was in Clare's that evening. I stood at the end of the bar, talking to Lynne who was working behind the bar serving drinks, crisps and nuts. 
There was line dancing on the dance floor, country music playing and scatters of talcum powder on the floor so the dancers would not lose their footing, a typical Wednesday night. A man named Dave was in Clare's. I had never met Dave before, despite having lived in Higher Blackley for nine months already. He approached me when I was standing alone at the far end of the bar, because, he explained, he had heard my "foreign accent". Dave stared at me for a moment and then said, "You're a fucking South African, aren't you?" I told him that I am originally from California. He then said to me that he could tell by my accent that I was a South African and that he would "rather choke". I asked him why he would rather choke. Dave replied, "All South Africans are fucking white niggers; you're a white nigger. There ain't no black in the Union Jack! I'm white through and through!' Dave said this as he pounded on his chest with his fist, and then raised his fist into the air.

I felt intimidated, shocked and confused by Dave's actions. I felt restricted in my movement and I searched for words to say in response. I searched my thoughts and wondered whether Dave was being aggressive or aggressive in jest. At this point in my fieldwork I was beginning to question the boundaries of joking relationships in Higher Blackley, which often appear to be based upon aggression, but are transformative exchanges of insults, dislocating what insults may be "taken to mean" and expressed as terms of endearment. I decided to give Dave the benefit of the doubt and began to banter with him. I explained, "Well, I actually think there is a little black in the Union Flag, but it is really just to add emphasis and shading to the overall design." There was a brief silence before Dave brought his head close to mine. He pulled down his bottom lip, exposing his bottom teeth and the inside of his lip. As he was drawing his mouth close to my eyes and pausing for a moment, I could see what he was showing me. There was a tattoo on the inside of his bottom lip which read, "Fuck you". Perplexed, I simply said, "That must have hurt". Dave then drew his head back rapidly and brought it forward, headbutting me and knocking my glasses off my face onto the floor.

As I picked up my glasses, I searched around Clare's to see if anyone had witnessed what had just happened. There were line dancers dancing, loud music and Lynne serving drinks behind the bar. I could see that no one appeared to have noticed what just happened. I rubbed my nose to relieve the pain and realised that no longer was I intimidated by Dave or anything he could do. I no longer felt fearful. The moment he hit me, the fear left me. Now, I was incredibly angry and wanted to hit him back. I poked Dave's forehead with my forefinger, where it had hit my glasses saying, "My glasses left a mark!" Dave appeared vacant and confused, almost as though he did not know what he had just done.

I went to Lynne, who stood behind the bar, and explained to her, "That man, Dave, just called me a white nigger and headbutted me". Lynne did not appear surprised. She explained to me that Dave had experienced a "bad stint" in the army; he had found a mass grave and came back to Manchester with "serious mental problems". She went on to explain that Dave is a "right laugh" when he is sober, but when he has had a drink, he turns into a "right arsehole". This was the end of our conversation. Lynne did not mention my complaint to Dave; she continued to talk to him as if she knew nothing of what had just occurred. 


\section{"Stepping back" from a speedy step forward}

I was aware that there were certain social pressures which involved me "laughing it off". To "kick up a fuss" or to draw attention to Dave's actions (after speaking to Lynne) would have been profoundly inappropriate, especially considering that the local police and other juridical authorities are often placed outside of discourses of belonging and "fairness" in Higher Blackley. I walked outside of Clare's and phoned my husband to tell him what had just happened. My husband immediately told me to call the police and report the incident. I had not thought of calling the police. If I phoned the police, I would be drawing attention to Clare's, as a whole, for something which was supposed to be laughed off or shaken off. I felt disarmed and puzzled. I knew what was expected of me socially, but I did not know what to do next.

On the surface, there did not seem to be any logical thought process informing Dave's actions. Indeed, his actions were explained to me by Lynne as the actions of someone traumatised with "mental problems", and as something that should be endured. The "logic", provided indirectly by Lynne, came from a history, a personal biography that informed an unconventional, yet acceptable space within which Dave could safely remain. Lynne's explanations for Dave's actions, in a Foucauldian sense, provided a spatialisation and verbalisation of his pathological limits against an apparent background of objectivity, because everything about his "mental problems" were phenomena and essence which cannot be helped by Dave himself (Foucault 1989:111). It would have been profoundly "unfair" to have phoned the police, importing unnecessary elements into a situation which could easily be transgressed through making an "unfair" snap judgement. Lynne's information concerning Dave's traumatic military past was meant to provide me with an awareness of both Dave's place and general acceptance in Clare's, as well as a tool that I might use to affect future outcomes and respond in a socially appropriate manner. So I walked back to where I was living, to sit in my room and to begin typing up the events in my fieldwork diary.

What this incident also provided me with was a first-hand experience of what some racially differentiated individuals may have to deal with on a day-to-day basis. In addition, I deeply felt and embodied for a moment the aggression and desire for retaliation that some individuals may experience when faced with one's own reification and physical violence. The fear went and then I was angry. Equally significant, many conflicting and imposing interpretations and understandings of what constitutes not only racism but appropriate responses to a physical assault came to the fore. My own personal understandings of what racism was as well as what constituted an appropriate response did not, I soon learned, necessarily connect up with other's understandings in Higher Blackley.

Similar daunting conflicts have been addressed and discussed recently in a special issue for the journal Social Anthropology. Originating from the Young Scholars' Forum for the 2004 European Association of Social Anthropologists (EASA) Conference in Vienna, where $\mathrm{PhD}$ candidates in social anthropology were invited to address the general theme "Face-to-face: Connecting distance with proximity", the contributors to this special journal issue were encouraged to think ethnographically about the relationships through which anthropologists habitually conduct fieldwork and how these may affect the "discomfort of proximity" for the researcher (Harvey and Fillitz 2006:219), especially for the novice ethnographer. One of the contributors to this issue, Ruy Llera Blanes (2006), explained some of the discomforts of this 
reconciliation in his fieldwork that I could relate to. Llera Blanes conducted multisited fieldwork in Lisbon and Madrid amongst Presbyterian churchgoers. Llera Blanes identified himself as "atheist". However, he was finding access to interviews and church gatherings rather difficult to begin with because of his self-identification, which his "informants" regularly asked him about. He often found himself in a predicament as he faced the realisation that an aspect of his "self", which he felt to be personal and unchangeable, was seen by others as something that had the possibility of changing. He learned only through conversations and interactions with others in the course of fieldwork that, because of his honest commitment to dialogue with individuals in fieldwork, he could simply acknowledge the possibility that his personal religious beliefs might be changed; some day, he might just be "touched by God", but it turned out to be acceptable that it was not that particular day.

This understanding, for Llera Blanes, only came through the experience of personal and social conflicts that had to be experienced to be resolved. Importantly, Llera Blanes's work demonstrates the lawless interplay between methodological approaches and ethical standpoints as well as the fact that even the most seemingly innocent of attempts to remain distanced from the discourse and actions of others in the field must be examined, challenged, re-evaluated and presented in an ethical and sensitive fashion in both research and writing. This ultimately demands the recognition that attempts at utter objectivity and/or detachment from situations or individuals is virtually impossible; rather, objectivity can be desired, invented and personal for each researcher in any given moment. Appreciably, Llera Blanes's work (and the work of his co-contributors to this special issue) also demonstrates the uniqueness of personal challenges and conflicts in fieldwork. So then, what does it mean to have attempted such distancing in my fieldwork; notably, here, contending with it after the fact?

\section{"Passionate detachment" and the fragmentation of the self}

Debates concerning the notion of objectivity in the social sciences frequently take into account the work of Max Weber. A Weberian notion of "passionate detachment" consists of holding polar orientations in tension (Weber 1978:213-214), or at least, in my case, remaining aware of the potential polar orientations which I constructed when necessary, rather than remaining, in the name of scientific impartiality, unmoved by moral concern. A Weberian tradition stresses the importance of value-free interrogations of the social world within which we may find ourselves (Rosaldo 1993, Weber 1978). For instance, in Clifford Geertz's (1968) essay, "Thinking as a moral act: dimensions of anthropological fieldwork in the New States", Weber's notions of "passionate detachment" and "science as a vocation" lead Geertz to explore the idea that ethnographic fieldwork as a form of conduct involves a "tension between scientific understanding and moral perception, between a disciplined form of inquiry and the practical activities of everyday life" (Geertz 1968:154, cited in Rosaldo 1993:173-174). So in other words, according to Geertz, ethnographic research involves a personal subjection to a vocational ethic.

Thus, feelings which appear unworthy from a strict Weberian perspective can provide an insight into the search for a shared or common sense of emotions; however, the concept of emotion and the various emotions that may or may not be within and between groups of people are socially and culturally constructed, but individually felt. Rather than assume that my fear and anger in response to Dave's actions were necessarily comparable to another person's emotional reactions in a violent situation, 
I prefer to accept the contradictions in the idea that it might not be possible to compare, but that it might instead be useful to monitor the reactions and subsequent influences they may have on others and on situations.

When my emotions became noticeable, when my feelings were hurt, when I was angry, offended, upset, or even physically assaulted, I eventually found some comfort in putting the events and my experiences into an "analytical perspective" if only to simply feel as if I had distanced myself from the particular situation; to feel that what happened is now in the past and will ultimately be useful for my overall purpose for being here. This epistemological approach of attempting to create some sort of distance between my emotions and my "analytical perspective" - this Weberian approach to a "passionate detachment" - did, in many ways, help, if only as a temporary remedy in struggles for power, feelings of homesickness, fear, anger and unhappiness. However, although this way of thinking did seem to help me, personally, during troublesome times in fieldwork, and particularly after Dave's physical assault, it transformed my fieldwork and my position in Higher Blackley into something very specific: conjunctural and unique.

Neglecting to examine the encounters and methodological approaches of the anthropologist and their hosts has been argued to deny the power of such factors as "personality, social location in the community, intimacy of contact and general luck" (Abu-Lughod 1999:27). There are the experiences and information of others, given to the researcher, from informants, which also forms the "cultural exchange of information" (Harvey and Fillitz 2006:221) and the crux of the ethnographic project itself (Geertz 1988). Reflecting upon my fieldwork experiences, understanding them and remaining explicit in my representations of them has allowed me to relate to Coffey's (1999:35) important insight into the "fragmentation of the self", the idea that the fragmentation of our lives, as anthropologists in fieldwork, can throw our own perspectives of who we are and where we belong into chaos, and that "the balance between strangeness and familiarity, often expressed in pragmatic terms, is not easily negotiated yet is not fixed, not singular and not bounded". Moreover, once these obstacles are explicitly established in reflexive analysis, one can be aware of these issues during fieldwork and "pursue a line of inquiry that does not promote a stereotypical view of the 'other', even if the 'other' remains a problematised concept" (Coffey 1999:35), or harnessed within a problematised concept such as "racism".

The emotional reactions of researchers in fieldwork are inextricably tied up with both our research methods and writing up (Hovland 2007). Just as theoretical frameworks are informed, challenged and ever-changing through the course of fieldwork, it is inevitable that our methods concerning the pursuits of situated knowledges must be as reactionary and tentative as our emotional responses to situational contexts. There may be perceived conflict between individual ethical, moral and, thus, political standpoints - for instance, what some may view as grounded and unchanging moral beliefs, others may view as changeable or, perhaps, easily influenced (cf. for example Llera Blanes 2006). The positioning of the individual may be challenged, questioned, disturbed, as we attempt to honestly engage and apply commitment to a dialogue with others. 


\section{Conclusion}

My personal ethical and political standpoints and opinions prior to and during fieldwork very much affected the outcomes of my research and writing up, as they were challenged when faced with particular logics in discourses on race, gender and ethnicities (cf. Tyler 2007). Without wanting to pathologise the emotional reactions I experienced in fieldwork to situations and actions that I found uncomfortable and even dangerous, the purpose of this paper has been to provide an example of how I dealt with personal struggles and the ways in which I came to terms with my objectives for conducting research in the first place. Through asking the rhetorical question "Is a happy anthropologist a good anthropologist?" many avenues of my fieldwork experience became available for further interpretation. Certainly, issues of ethical and reflexive research strategies have been a consistent element of anthropological discourse for some time; however, there is still a growing body of literature, particularly contributed to by young scholars, which offers fresh perspectives on issues that novice ethnographers may find testing in the act of fieldwork itself. The mystique of fieldwork, as taught, as explained in attempts to prepare the novice ethnographer, soon feigned for me in the demystifying processes and transformations of fieldwork.

There are multiple sources of knowledge in social analyses and I am not upholding detachment as a unified standard of objectivity for exploring "cultural facts". However, scholars such as Veronica Strang (2003:172), who has noted that the lack of any claims to objectivity undermines anthropology and its usefulness, and also undermines cross-cultural comparison, have also contributed to debates concerning claims to "objectivity", universality and/or postmodern, culturally relativistic, interpretive endeavours. Here, however, I have focused upon how a novice researcher dealt with her own personal struggles in fieldwork. I concede that what I may have once thought of as "analytical perspective" or a "passionate detachment" was really, for me, part of the very fabric of my fieldwork, entangled and contingent upon all other aspects; not a separation at all but a result of the "self" that I brought into the field. The fragmentation of that self as well as its multiple, situated positionings at once underscore the potential for uniting an analytical with an ethical project and renders obsolete the view of the utterly detached observer. The long-standing debates in the social sciences between striving towards a postmodern, interpretive researcher and a more observant, perhaps more stoic researcher have been useful tools with which to think through my fieldwork experiences and methodological and/or ethical predicaments. However, I learned through my own experiences in fieldwork, particularly with Dave in Clare's, that it may not be possible to completely obtain an adequate "distance" for emotional disengagement; but there is the possibility for the invention of a "passionate detachment" by the researcher in any given moment. The necessity for such invention, for me, allowed me to recognise that in many respects my fieldwork could, at once, be done, be useful and be lived, if only by simply feeling that as a happy anthropologist, I could be a good anthropologist.

\section{References}

Abu-Lughod, L. 1999. Veiled sentiments: honor and poetry in a Bedouin society. Berkelely, CA: University of California Press.

Adler, P.A. and P. Adler. 1998. Foreward: moving backward. In Ethnography at the 
edge: crime, deviance and field research, eds. J. Ferrell and M.S. Hamm, xiixvi. Boston: Northeastern University Press.

Agar, M. 1980. The professional stranger: an informal introduction to ethnography. New York: Academic Press.

Burgess, R. 1984. In the field: an introduction to field research. London: Unwin.

Caplan, P. 2003. Introduction. In The ethics of anthropology: debates and dilemmas, ed. P. Caplan, 1-34. New York: Routledge.

Coffey, A. 1999. The ethnographic self: fieldwork and the representation of identity. London: Sage.

Ellen, R. 1984. Ethnographic research: a guide to general conduct. San Diego: Academic Press.

Eriksen, T.H. 1991. A community of European social anthropologists. Current Anthropology 32(1), 75-78.

Ferrell, J. and M.S. Hamm. 1998. True confessions: crime, deviance and field research. In Ethnography at the edge: crime, deviance and field research, eds. J. Ferrell and M.S. Hamm, 2-19. Boston: Northeastern University Press.

Foucault, M. 1989. The birth of the clinic: an archaeology of medical perception, trans. A.M. Sheridan. New York: Routledge.

Geertz, C. 1968. Thinking as a moral act: ethical dimensions of anthropological fieldwork in the New States. The Antioch Review 28(2), 139-158.

--------. 1988. Works and lives: the anthropologist as author. Cambridge: Polity Press.

Gupta, A. and J. Ferguson. 1997. Discipline and practice: "the field" as site, method, and location in anthropology. In Anthropological locations: boundaries and grounds of a field science, eds. A. Gupta and J. Ferguson, 1-46. Berkeley: University of California Press.

Haraway, D. 1991. Situated knowledges: the science question in feminism and the privilege of partial perspective. In Simians, cyborgs and women: the reinvention of nature, ed. D. Haraway, 183-202. New York: Routledge.

Harvey, P. and T. Fillitz. 2006. Introduction: threatening communication: the discomfort of proximity. Social Anthropology 14(2), 219-222.

Hastrup, K. and P. Elsass. 1990. Anthropological advocacy: a contradiction in terms? Current Anthropology 31(3), 301-311.

Hendry, J. 1992. The paradox of friendship in the field: analysis of a long-term Anglo-Japanese relationship. In Anthropology and autobiography, eds. J. Okely and H. Callaway, 163-174. New York: Routledge.

Hovland, I. 2007. Writing up and feeling down: introduction. Anthropology Matters Journal 9(2), 1-4 (www.anthropologymatters.com/journal).

Llera Blanes, R. 2006. The atheist anthropologist: believers and non-believers in anthropological fieldwork. Social Anthropology 14(2), 223-224.

Marcus, G. 1995. Ethnography in/of the world system: the emergence of multi-sited ethnography. Annual Review of Anthropology 24, 95-117. 
Piña-Cabral, J. 2000. The ethnographic present revisited. Social Anthropology 8(3), 341-348.

Rapport, N. 2002. Post-cultural anthropology: the ironisation of values in a world of movement. In Realising community: concepts, social relationships and sentiments, ed. V. Amit, 146-164. New York: Routledge.

Rosaldo, R. 1993. Culture and truth: the remaking of social analysis. Boston: Beacon Press.

Strang, V. 2003. An appropriate question? The propriety of anthropological analysis in the Australian political arena. In The ethics of anthropology: debates and dilemmas, ed. P.Caplan, 172-194. London: Routledge.

Tyler, K. 2007. "Streetville forever": collective action, ethnicity and the state. Identities: Global Studies in Culture and Power 14(5), 579-602.

Weber, M. 1978. Politics as a vocation. In Weber: selections in translation, ed. W.G. Runciman, trans. E. Matthews, 212-225. Cambridge: Cambridge University Press.

\section{About the author}

Katherine Smith conducted 12 months of ethnographic fieldwork in North Manchester, England, exploring idioms of "fairness", social exclusion and belonging. Her doctoral thesis, "The Outside Within: Belonging, Fairness and Exclusion in Higher Blackley, North Manchester" was submitted in September, 2008. 